\title{
The comparative biology of the solitary endoparasitoid Meteorus gyrator (Hymenoptera: Braconidae) on five noctuid pest species
}

\author{
Fiona SMETHURST, Howard A. BELL*, H. June MATTHEWS and John P. EDWARDS \\ Central Science Laboratory, Sand Hutton, York, YO41 1LZ, UK
}

Key words. Parasitoid, Spodoptera, Mamestra brassicae, Chrysodeixis chalcites, Lacanobia oleracea, insect pests

\begin{abstract}
The comparative biology of the solitary endoparasitoid Meteorus gyrator (Thun.) was investigated in five noctuid pest species. Meteorus gyrator parasitized all larval stages of the noctuid pests Lacanobia oleracea, Mamestra brassicae, Spodoptera exigua, Spodoptera littoralis and Chrysodeixis chalcites. When female parasitoids were offered host larvae of all developmental stages, host larvae in their third stadium were parasitized most frequently in all species. When the parasitoid was offered a choice of third stadium larvae from each of the five lepidopteran host species, $L$. oleracea was the most frequently parasitized, followed by $M$. brassicae. The growth of L. oleracea and M. brassicae was markedly reduced when larvae were parasitized by $M$. gyrator, with the effect of parasitism on the remaining species being much less pronounced. In excess of $94 \%$ of parasitized hosts gave rise to live wasps in L. oleracea, whilst in M. brassicae only $52 \%$ of parasitized hosts gave rise to a live wasp, the remainder dying (44.6\%) or pupating $(3.1 \%)$.

The larval development of the parasitoid was also strongly influenced by the host species. Thus, the development (egg to cocoon) of female wasps was most rapid in C. chalcites $(9.7 \pm 0.09$ days $)$, and longest in $M$. brassicae $(17.2 \pm 1.08$ days). The cocoon weight of wasps was also significantly affected by host species, with the heaviest female cocoons being derived from C. chalcites (10.4 \pm $0.16 \mathrm{mg})$ and the lightest female cocoons being derived from M. brassicae $(7.0 \pm 0.14 \mathrm{mg})$. In all cases, the development times and cocoon weights of male parasitoids were less than those of female wasps.
\end{abstract}

\section{INTRODUCTION}

Meteorus gyrator (Thun.) (Hymenoptera: Braconidae) is a solitary endoparasitoid which has a wide geographical distribution, occurring throughout the British Isles and northern Europe as well as north Africa and Asia (Thompson, 1953). This parasitoid has a wide host range within the Lepidoptera, and attacks several noctuid, geometrid and lymantriid species (Kotenko, 1976; Askew \& Shaw, 1986; Goto et al., 1986). The meteorine wasps constitute a relatively under-researched assemblage, and although some information is available on some other species (Simmonds, 1947; Askari et al., 1977; Thireau et al., 1990), there is very little information on M. gyrator. Thus, with the exception of the studies of Bell et al. (2000a) in larvae of the tomato moth, Lacanobia oleracea (L.), and those of El-Sheikh et al. (1993) in larvae of Mythimna loreyi (Duponchel), no information is available on the performance of this parasitoid against other pest species.

The larvae of a wide range of lepidopteran species attack field and glasshouse crops in the UK and Europe (Foster, 1981; Van de Veire, 1993). For this reason, there is a constant requirement to identify and develop biological control agents. Bell et al. (2000b) indicated that this parasitoid may have potential as a biological control agent against lepidopteran larvae in the glasshouse, although little information is available as to its success on hosts other than L. oleracea. Furthermore, a wide range of parasitoid species have been investigated because of their ability to regulate the development of their hosts through the use of venoms, polydna viruses and teratocytes in order to produce a favourable environment for the development of their larvae (reviewed by Strand \& Pech, 1995). Failure to develop within a given host can frequently be attributed to the inability of the parasitoid to successfully regulate their host through disruption of their endocrinology or suppression of the immune response (Vinson \& Iwantsch, 1980; Edwards et al., 2001).

The investigation of the success of $M$. gyrator within a range of hosts, and differences in the biology of the parasitoid when developing in different species, is required in order to lay the foundations for the examination of further parasitoid-host interactions aimed at investigating the factors that may contribute to its successful development. The work presented here reports on a series of experiments designed to determine the potential of this parasitoid to parasitize and develop in a range of pest noctuids. Specifically, we have examined some aspects of the basic biology of $M$. gyrator in five noctuid species viz. Spodoptera exigua (Hübner), Spodoptera littoralis (Boisd.), Mamestra brassicae (L.), Lacanobia oleracea (L.) and Chrysodeixis chalcites (Esper).

\section{MATERIALS AND METHODS}

\section{Test insects}

The noctuid larvae used in these experiments were derived from standard laboratory cultures maintained at the Central Science Laboratory (CSL). The procedures for culturing the five test species were all essentially the same, and followed the procedures outlined by Corbitt et al. (1996) for L. oleracea. Prior to

\footnotetext{
* Corresponding author. E-mail: h.bell@csl.gov.uk; phone: 01904 462669; fax: 01904462111
} 
TABLE 1. The proportion of hosts of any given larval instar parasitized for four of the test species. For each replicate, five hosts from each larval instar were exposed to a single mated female $M$. gyrator for 48 hours and dissected after four days to confirm the presence of parasitoid larvae/eggs. Values followed by different letters within rows are significantly different (one-way ANOVA followed by Tukey-Kramer post hoc tests, $\mathrm{P}<0.05$ ).

\begin{tabular}{lcccccccc}
\hline \multirow{2}{*}{ Species } & \multirow{2}{*}{$\begin{array}{c}\mathrm{n} \\
\text { Reps }\end{array}$} & \multicolumn{5}{c}{$\%$ of total parasitism within each instar } \\
\cline { 3 - 8 } & & parasitized & $\mathrm{I}$ & $\mathrm{II}$ & $\mathrm{III}$ & $\mathrm{IV}$ & $\mathrm{V}$ & VI \\
\hline L. oleracea & 30 & 159 & $3.8 \mathrm{a}$ & $9.4 \mathrm{~b}$ & $66.7 \mathrm{c}$ & $15.7 \mathrm{~b}$ & $1.9 \mathrm{a}$ & $2.5 \mathrm{a}$ \\
M. brassicae & 30 & 206 & $3.9 \mathrm{a}$ & $23.3 \mathrm{~b}$ & $60.1 \mathrm{c}$ & $8.3 \mathrm{a}$ & $2.9 \mathrm{a}$ & $1.5 \mathrm{a}$ \\
S. littoralis & 30 & 71 & $4.3 \mathrm{a}$ & $8.5 \mathrm{a}$ & $50.7 \mathrm{~b}$ & $19.7 \mathrm{ab}$ & $15.5 \mathrm{ab}$ & $1.3 \mathrm{a}$ \\
S. exigua & 30 & 172 & $4.1 \mathrm{a}$ & $15.1 \mathrm{bc}$ & $52.9 \mathrm{~d}$ & $19.2 \mathrm{c}$ & $6.9 \mathrm{ab}$ & $1.8 \mathrm{a}$ \\
\hline
\end{tabular}

use, L. oleracea were maintained under constant conditions $\left(20^{\circ} \mathrm{C}, 65 \%\right.$ r.h., $\left.16 \mathrm{~L}: 8 \mathrm{D}\right)$. All other species were maintained at $25^{\circ} \mathrm{C}, 70 \%$ r.h., $16 \mathrm{~L}: 8 \mathrm{D}$. Larvae of all five species were provided with artificial noctuid diet (Bioserv, New Jersey, USA) based on maize flour (Poitout \& Bues, 1974). Developmental stages were distinguished on the basis of head capsule width. Meteorus gyrator adults were derived from a laboratory culture $\left(25^{\circ} \mathrm{C}, 70 \%\right.$ r.h., $\left.16 \mathrm{~L}: 8 \mathrm{D}\right)$ reared on L. oleracea larvae. The origin and culturing of the $M$. gyrator used in these experiments has been described elsewhere (Bell et al., 2000a).

\section{Host stages selected for parasitism}

Five newly-moulted larvae from each of the six larval stadia (i.e. 1st to 6th instar larvae) of each of L. oleracea, S. littoralis, S. exigua, and M. brassicae were placed into plastic boxes (150 $\times 150 \times 75 \mathrm{~mm}$ ) and provided with noctuid diet ad libitum. A single, newly-emerged, mated $M$. gyrator female, without prior access to hosts, was released into each box and provided with a $50 \% \mathrm{v} / \mathrm{v}$ aqueous honey solution as a food source. Forty-eight hours after their introduction the parasitoids were removed from the plastic boxes and the host larvae were grouped by stadium and placed in tissue-lined $250 \mathrm{ml}$ plastic pots. The larvae were subsequently supplied with artificial diet ad libitum and maintained under constant conditions $\left(25^{\circ} \mathrm{C}, 70 \%\right.$ r.h., 16L : 8D). Four days post-parasitism (parasitoid eggs hatch on the 3rd day post oviposition) the host larvae were dissected, and the presence of parasitoid eggs or larvae determined. The number of parasitized larvae from each host stadium was recorded.

\section{Choice of host species}

Five newly-moulted third instar larvae from each of $L$. oleracea, S. littoralis, S. exigua, M. brassicae and C. chalcites were placed together in plastic boxes $(150 \times 150 \times 75 \mathrm{~mm})$ and provided with noctuid diet ad libitum. These groups of hosts were then exposed to a single, newly-emerged, mated $M$. gyrator female for 48 hours. The hosts were then collected and maintained as described above. The hosts were kept for 2-3 days to allow any eggs present to grow to a readily discernible size and were then dissected to determine the presence or absence of eggs or parasitoid larvae.

\section{Parasitoid development and effects on host growth}

Newly-moulted third instar larvae of each host species were placed in groups of 20 into plastic boxes $(150 \times 150 \times 75 \mathrm{~mm})$ and provided with noctuid diet ad libitum. Newly emerged, mated M. gyrator females were released into each box at a ratio of one wasp to five host larvae (a ratio sufficient to ensure that the majority of potential hosts were parasitized) and provided with a $50 \% \mathrm{v}: \mathrm{v}$ aqueous honey solution food source. Twentyfour hours after initial exposure to hosts, parasitoids were removed from the test arenas. The host larvae were subsequently placed individually into $250 \mathrm{ml}$ plastic pots and maintained as above until all hosts had produced a wasp, pupated or died. The duration of the development of the parasitoid (egg to cocoon), the weight of cocoons (within 24 hours of egression from the host) and the sex of each wasp upon adult emergence were also recorded. Additionally, 15 unparasitized hosts (exposed to male wasps only) and a selection of the parasitized hosts (up to 30) were weighed daily to ascertain the effect of parasitism on the growth of the respective host species. A total of 150-300 wasp-exposed insects were monitored for wasp development for each test species, depending on the rates of parasitism and the successful development of the parasitoid within a given host. Hosts that did not yield a live wasp were discarded for all species.

\section{Parasitoid success in different hosts}

To determine the proportion of parasitized hosts that successfully yielded live wasps, groups of five larvae of each of the test species (excluding C. chalcites) were exposed to a single female $M$. gyrator overnight in a $12 \mathrm{~cm}$ diameter Petri dish. After exposure to the wasp, each larva was placed individually in a $250 \mathrm{ml}$ plastic pot and supplied with artificial diet ad libitum. This was repeated twenty times such that a total of 100 larvae of each moth species were exposed to M. gyrator in this way. All larvae were subsequently monitored for parasitoid emergence, death or pupation. On death or pupation, hosts were dissected to determine the presence of parasitoid eggs or larvae. Similarly, the frequency of superparasitism was investigated by dissecting moribund hosts following the egression of the parasitoid larvae to determine the number of parasitoid first instar head capsules present (indicative of the number of parasitoid eggs that had hatched within each host) and for the presence of remaining live parasitoid larvae within them.

\section{Data analysis}

Datasets were analysed using two-way ANOVA (Minitab V13.3). Where necessary, proportions were subjected to angular transformation prior to analysis. Following ANOVA, differences between datasets were determined using Tukey-Kramer post hoc tests and the accepted level of significance was $\mathrm{P}<$ 0.05 in all instances. For the comparison of two means, Student's t-test was used.

\section{RESULTS}

\section{Host stages selected for parasitism}

For each of the host species tested, M. gyrator successfully parasitized all developmental stages presented to it and for all hosts significant differences were apparent in the proportions of the different instars parasitized (one-way ANOVA, P < 0.05) (Table 1). In all cases, the third larval stadium was the most frequently parasitized host stage - always representing more than $50 \%$ of the total number of hosts parasitized for each of the test species. In the cases of L. oleracea, S. littoralis and $S$. exigua, the fourth stadium was the next most frequently 


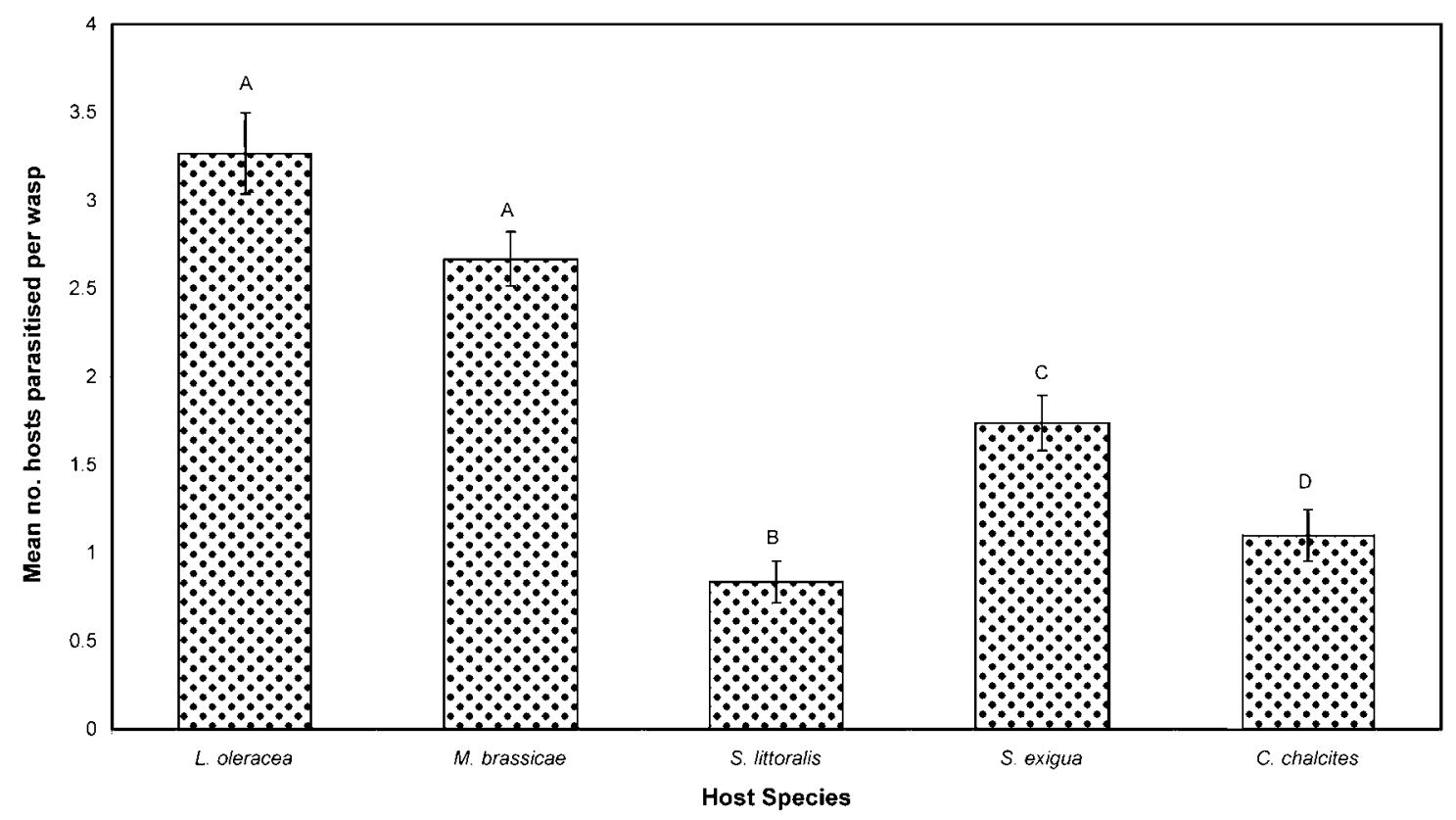

Fig 1. The mean number of hosts ( \pm SEM) selected for parasitism by M. gyrator. Mated female wasps were presented with five third instar hosts from each of the test species for 48 hours and parasitism subsequently determined by dissection. For each column, values followed by different letters are significantly different (one-way ANOVA, $\mathrm{P}<0.05$ ).

parasitized stage (15.7\%, 19.7\% and $19.2 \%$ respectively) followed by the second stadium $(9.4 \%, 8.5 \%$ and $15.1 \%$ respectively). However for $M$. brassicae this trend was reversed, the second stadium being the next most readily parasitized (23.3\% of total parasitism) followed by the fourth stadium (8.3\% of total parasitism). In all species tested, although the 1st, 5th and 6th stadia were also parasitized, parasitism of these stadia was generally less frequent.

Insufficient numbers of $C$. chalcites were available to conduct a comparable assessment of the most frequently parasitized stadium for this host. However, pilot studies (not reported here) also indicated that the third larval stadium of $C$. chalcites was also the stage most frequently parasitized by this wasp.

\section{Host species selected for parasitism}

Significant differences were recorded between the frequencies of parasitism of the different host species (one-way ANOVA, $F=35.1$, df $=4,145$, $\mathrm{P}<0.05$ ). Of the five host species presented to $M$. gyrator females in choice tests, $L$. oleracea larvae were the most frequently chosen for parasitism, with an average $3.3 \pm 0.23$ hosts parasitized per wasp (Fig. 1). However, all other test species were parasitized by $M$. gyrator, albeit to a lesser extent. Mamestra brassicae was the next most frequently parasitized host, with an average of $2.7 \pm 0.15$ hosts parasitized per wasp, whilst $S$. littoralis, $S$. exigua and $C$. chalcites gave averages ( \pm SEM) of $0.8 \pm 0.12,1.7 \pm 0.16$ and $1.1 \pm 0.13$ parasitized hosts per wasp, respectively.

\section{The development of $M$. gyrator on different hosts}

The development time (egg to cocoon) of M. gyrator developing within hosts parasitized as third instars was significantly affected by host species $(F=73.15$; $\mathrm{df}=4$, 322; $\mathrm{P}<0.001$ (Table 2). Similarly, the sex of the parasitoid also had a significant effect on development time ( $F$ $=8.29 ; \mathrm{df}=4,322 ; \mathrm{P}<0.01)$ and, irrespective of host species, male parasitoids developed more rapidly than their female counterparts. By the same token, the weight of the cocoons spun by the parasitoids following egression from the host was also significantly affected by the host species ( $F=55.15$; $\mathrm{df}=4,323$; $\mathrm{P}<0.0001)$ and the sex of parasitoid $(F=15.15 ; \mathrm{df}=4,323 ; \mathrm{P}<0.0001)$.

Wasps developed most rapidly in $C$. chalcites $(9.3 \pm$ 0.11 and $9.7 \pm 0.09$ days for male and female parasitoids,

TABLE 2. The mean development times of M. gyrator (egg-cocoon), and cocoon weights, in different candidate host species (days \pm SEM). For each parameter, values followed by different letters are significantly different (two-way ANOVA followed by TukeyKramer post hoc tests, $\mathrm{P}<0.05$ ).

\begin{tabular}{|c|c|c|c|c|}
\hline & \multicolumn{2}{|c|}{$\begin{array}{l}\text { Development time from egg - cocoon } \\
\text { Days }( \pm \text { SEM) }(\mathrm{n})\end{array}$} & \multicolumn{2}{|c|}{$\begin{array}{l}\text { Mean cocoon weight } \\
(\mathrm{mg} \pm \mathrm{SEM})(\mathrm{n})\end{array}$} \\
\hline & Males & Females & Males & Females \\
\hline L. oleracea & $10.6 \pm 0.17$ (46)ab & $11.6 \pm 0.28(51) b$ & $8.5 \pm 0.31$ (46)a & $9.8 \pm 0.37$ (51)b \\
\hline M. brassicae & $15.1 \pm 1.06$ (23)с & $17.2 \pm 1.08$ (27)d & $6.1 \pm 0.16(23) \mathrm{c}$ & $7.0 \pm 0.14(27) \mathrm{cd}$ \\
\hline S. littoralis & $11.5 \pm 0.10$ (26)be & $11.6 \pm 0.10(24) b$ & $8.0 \pm 0.08$ (26)ad & $8.3 \pm 0.09$ (24)ad \\
\hline S. exigua & $9.8 \pm 0.14$ (23)ab & $9.9 \pm 0.15$ (26)ab & $8.0 \pm 0.13(23) a$ & $8.4 \pm 0.13$ (27)a \\
\hline C. chalcites & $9.3 \pm 0.11(40) \mathrm{a}$ & $9.7 \pm 0.09$ (46)ае & $10.1 \pm 0.16(40) \mathrm{b}$ & $10.4 \pm 0.16(46) \mathrm{b}$ \\
\hline
\end{tabular}




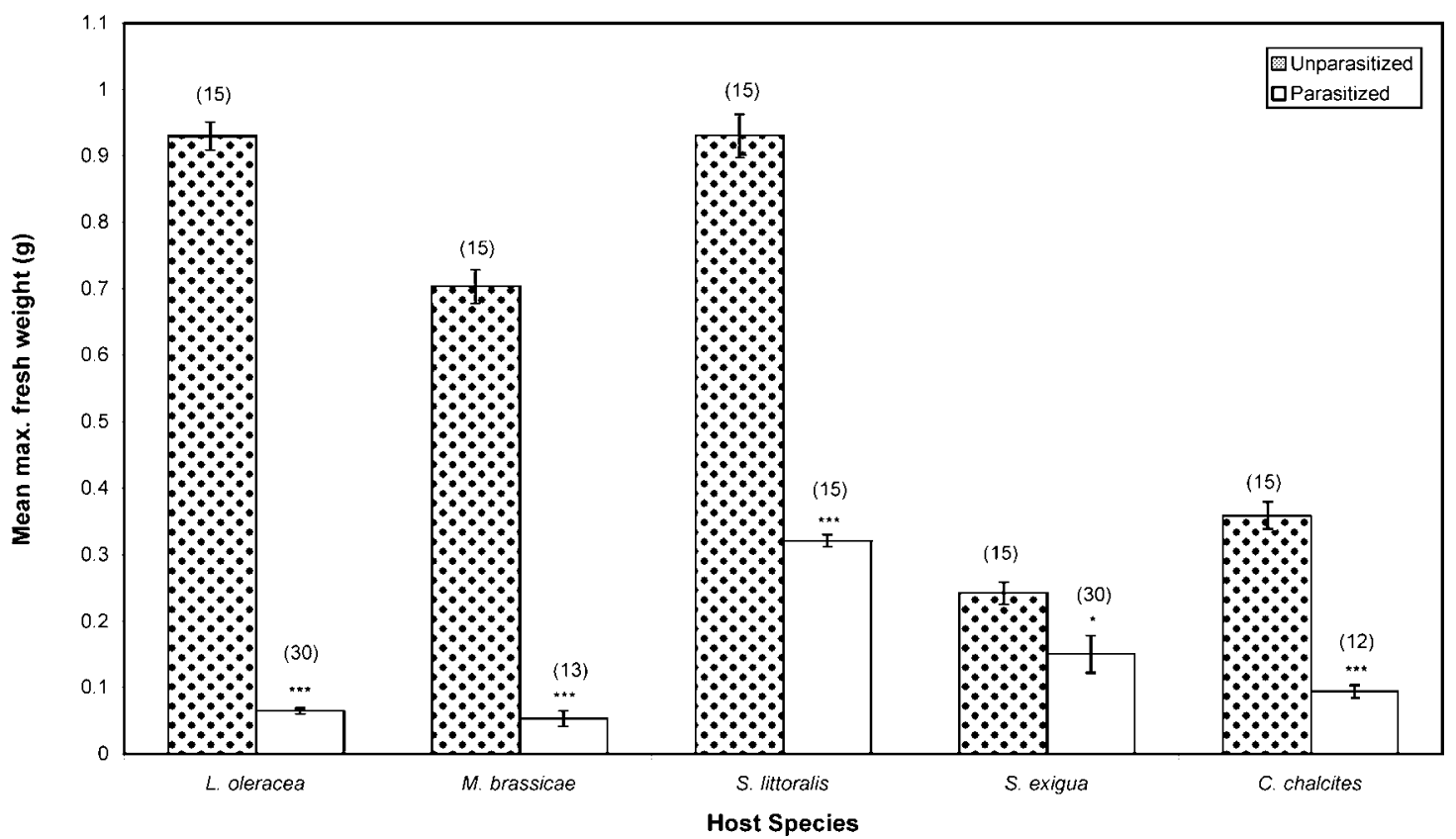

Fig 2. The maximum fresh weights achieved before pupation or death from parasitism by M. gyrator hosts for each of the test species $(\mathrm{g} \pm \mathrm{SEM})$. Hosts were parasitized at the beginning of the third larval stadium. Values were analysed using Student's t-test and significant differences in parasitized hosts when compared to their unparasitized counterparts are signified by $*$ and $* * *$ for $\mathrm{P}<0.05$ and $\mathrm{P}<0.001$.

respectively), and also gave the greatest mean cocoon weights at emergence $(10.1 \pm 0.16$ and $10.4 \pm 0.16 \mathrm{mg}$ for male and female parasitoids, respectively) in this host. In contrast, wasps developing in $M$. brassicae showed the slowest larval development time for both male (15.1 \pm 1.06 days) and female wasps (17.2 \pm 1.08 days) and also gave the smallest mean cocoon weights $(6.1 \pm 0.16$ and $7.0 \pm 1.5 \mathrm{mg}$ for male and female parasitoids, respectively). In the remaining species, cocoon weights were largely similar (8-9 mg).

\section{Effect on host growth}

The growth of hosts was significantly affected by parasitism in all host species examined when compared with unparasitized larvae (Student's t-test, $\mathrm{P}<0.05$ ). Fig. 2 shows the maximum weights attained by parasitized and unparasitized hosts for each of the test species. In L. oleracea, $M$. brassicae and $C$. chalcites, growth was rapidly suppressed such that parasitized hosts were markedly smaller than unparasitized hosts after 4-5 days. However, for both $S$. littoralis and $S$. exigua no reduction in growth was observed during the parasitoid's developmental period. The difference in the growth of parasitized and unparasitized larvae was most pronounced in the case of L. oleracea, where the mean maximum weight attained by parasitized larvae was only $6.9 \%$ of that of nonparasitized hosts. Similarly, parasitized $M$. brassicae larvae reached a maximum weight only $7.6 \%$ of the weight reached by non-parasitized larvae, whilst $C$. chalcites grew to $26.1 \%$ of the weight of unparasitized hosts. However, in the case of $S$. exigua and S. littoralis the mean maximum weight reached by parasitized larvae was $62.0 \%$ and $34.5 \%$ respectively, of the maximum weights reached by non-parasitized controls. In both these cases, these differences were largely due to growth of unparasitized hosts after the time when parasitoids had emerged from the parasitized hosts, and not due to suppression of growth during parasitism (growth curves not shown).

\section{Developmental success of $M$. gyrator}

Live parasitoids emerged from over 94\% of parasitized L. oleracea, with no parasitized hosts pupating (Fig. 3). However, in $M$. brassicae only $52 \%$ of parasitized hosts gave rise to live wasps with the remainder either dying during development, or pupating. Moreover, whilst live parasitoid larvae were never found in L. oleracea following the egression of the first wasp, in M. brassicae $45 \%$ of hosts that had produced a live parasitoid had at least one live wasp larva remaining within the moribund host. In S. littoralis, whilst fewer hosts were parasitized (as determined by dissection of dead hosts or by wasp emergence), only $7.5 \%$ of hosts that produced live wasps still contained a live wasp larva and in only one instance was evidence of parasitism found in a host that had pupated. The majority of parasitized $S$. exigua hosts gave rise to live wasps (ca. 83\%) and no hosts contained live parasitoid larvae following egression of the first parasitoid or showed evidence of parasitism on dissection following pupation.

Dissections of all hosts following egression of the parasitoid revealed that self-superparasitism was common and had occurred in all species. The number of parasitoid first instar head capsules was used as a measure of the number of eggs that had been oviposited within each host. An average of $1.4 \pm 0.08$ head capsules were found in parasitized $L$. oleracea with $80 \%$ of exposed hosts being parasitized. However, in $M$. brassicae an average of $4.3 \pm 0.44$ were counted with $66 \%$ of total number of exposed hosts 


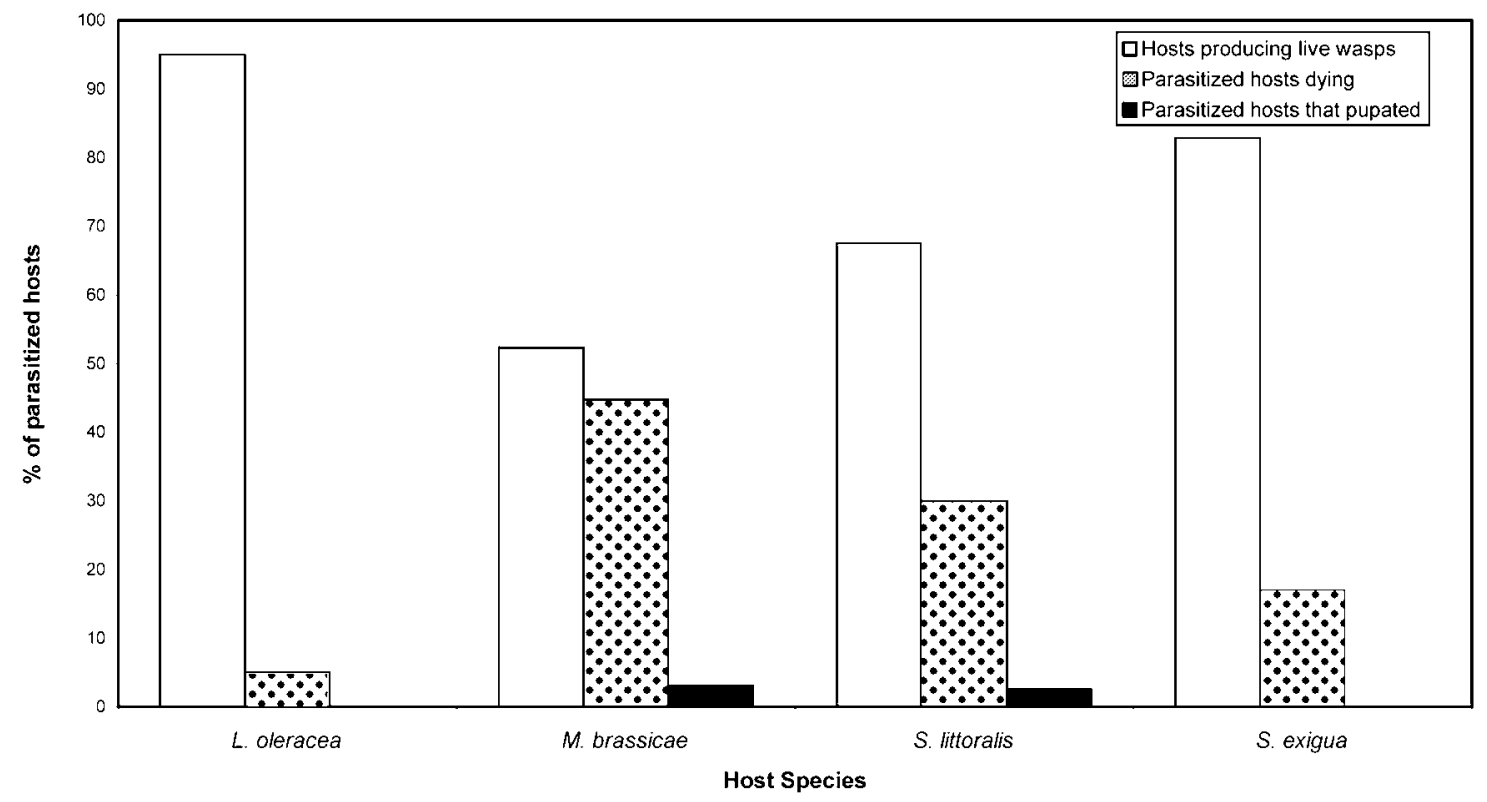

Fig 3. The relative success of $M$. gyrator when developing in different noctuid host species. Bars represent the proportion of parasitized hosts that yielded a live wasp, those that died during parasitism and the proportion of hosts that pupated but had parasitoid head capsules present on dissection. The line represents the proportion of the total number of hosts that were parasitized $(\mathrm{n}=100$ hosts) after exposure to a single $M$. gyrator female for 24 hours in groups of five.

being parasitized. Spodoptera littoralis was the most heavily superparasitized with an average of $5.0 \pm 0.89$ head capsules present in each parasitized host, despite only $40 \%$ of exposed hosts being parasitized whilst $S$. exigua gave a value of $2.2 \pm 0.25$ head capsules per host (35\% parasitism).

\section{DISCUSSION}

In these experiments we have shown that the parasitoid $M$. gyrator was able to attack all larval stages of the five noctuid species tested. In all of these species, the third larval stadium was the most frequently parasitized developmental stage. Lacanobia oleracea was the most frequently parasitized species in host choice tests. However, it has been postulated that wasps reared on a particular host may subsequently preferentially parasitize the same host species (Smith \& Cornell, 1979; Cortesero \& Monge, 1994). It has been suggested that parasitism of the same host species in which the parent wasp developed may have an adaptive advantage as such behaviour could contribute towards ensuring the successful development of a wasp's offspring (Rojas et al., 1999). To a degree, the levels of parasitism relative to the other test species observed in L. oleracea may be a reflection of this fact and this phenomenon requires further investigation.

Parasitism by $M$. gyrator resulted in a rapid reduction in the growth rate of host larvae of three of the noctuid species tested, with the ultimate weight achieved by all parasitized host species being significantly lower than unparasitized insects. In the case of S. littoralis, however, no effect on the growth of parasitized hosts was detected during the period of the parasitoid's larval development although unparasitized hosts did grow significantly larger subsequent to the time that parasitoids had emerged from parasitized hosts. For S. exigua, the difference in the ulti- mate weights achieved between parasitized and unparasitized hosts was relatively small, whereas in the other host species the growth rates were markedly different. Spodoptera exigua is naturally the smallest of the hosts tested here, and it is possible that the observed reduced impact of parasitism on the growth of this species may have been consequence of the smaller size of this host. It would therefore appear that $M$. gyrator allows hosts to grow to a largely similar size, irrespective of the species parasitized, in order for there being sufficient resource available for its successful development.

The developmental times and cocoon weights for $M$. gyrator reared on different host species may give some indication of the suitability of the different host species for this parasitoid. In general, as the suitability of a host decreases, so the developmental time of the parasitoid increases, and the resulting cocoon weight decreases (Harvey et al., 1999). It was, however, noted that the development times of the parasitoid within the different host species appeared to be correlated with the speed of development of the host; most rapid wasp development was observed in $C$. chalcites which shows the most rapid larval development, whilst development was slowest in $M$. brassicae, the moth with the longest larval development. A further indication of the suitability of a host may be derived by examining the survival of the host following parasitism. When the survival of parasitized hosts was assessed, only $5 \%$ of parasitized $L$. oleracea hosts died during parasitism whilst approximately $45 \%$ of parasitized $M$. brassicae died before the egression of the parasitoid larvae. The Spodoptera species were intermediate in their ability to support parasitoid development, with $68 \%$ and $83 \%$ of parasitized host producing live wasps for $S$. littoralis and $S$. exigua, respectively. It must be noted, however, that these values for the successful 
development of the parasitoid were derived from hosts that were determined to be parasitized by the presence of parasitoid larvae and head capsules and do not take into account the possibility that some eggs may have been encapsulated before hatching. The complete absence of encapsulated eggs on dissection of the hosts indicates that this may be, however, a rare event.

Whilst M. gyrator is a solitary endoparasitoid, with only one parasitoid ever emerging from a given host, it was observed that in M. brassicae and, to a lesser extent, $S$. littoralis, live wasp larvae were frequently found within hosts from which a parasitoid larvae had already egressed. It is generally thought that parasitoid larvae in superparasitized hosts eliminate all competing parasitoid larvae before moulting to the second stadium, however in the case of these two "poorer" hosts this did not always occur and perhaps further indicates that the parasitoid is less well adapted to these host species. In all of the species tested superparasitism was seen to occur, as determined by the dissection of hosts after egression of the parasitoid larvae. It was noted that superparasitism was lowest in the host species that gave the highest success rate in terms of parasitoid development (L. oleracea and $S$. exigua), whilst in M. brassicae and S. littoralis, where poorer rates of survival were recorded post-parasitism, superparasitism was higher. These high levels of superparasitism may have been a contributory factor in the higher levels of mortality observed in these hosts and may indicate that the parasitoid is less well adapted to these hosts. Superparasitism is generally considered to be maladaptive for solitary parasitoids (Godfray, 1994) although it has frequently been observed in $M$. gyrator, even when a large excess of unparasitized hosts are available $(\mathrm{H}$. Bell, unpublished observations) and may indicate that this parasitoid is unable to distinguish hosts previously parasitized by self or conspecifics. The small number of hosts available to the ovipositing parasitoid ( 5 per host for 24 hours) may have exacerbated the occurrence of superparasitism although it was noted that, particularly in the case of the Spodoptera species, unparasitized hosts were available to the majority of wasps at the end of the experiment. However, there is the potential that superparasitism may be a consequence of the strategy of this wasp to parasitize any suitable host that it encounters, regardless of its developmental stage or whether it is already parasitized. Further studies into the ovipositional behaviour of M. gyrator are currently ongoing in order to clarify this aspect of the parasitoids behaviour.

Bell et al. (2003) reported that this parasitoid could parasitize and develop in all larval stages of $L$. oleracea that it was presented with. However, the potential for this parasitoid to parasitize a range of hosts had not been investigated. Here we report that this parasitoid is capable of parasitizing all larval stages of a range of economically important species that frequently occur as glasshouse pests in Europe. Field studies, not reported on here, also indicate that this parasitoid can parasitize Autographa gamma (L.), Euplexia lucipara (L.) and several Mythimna species (H. Bell, unpublished data). It has also been reported to parasitize Trichoplusia ni (Hübner) (C. Bloemhard, personal communication).

The results would suggest that this parasitoid is best adapted to parasitizing L. oleracea, and S. exigua, with high host mortality reducing its success in $S$. littoralis and M. brassicae. Atypical parasitoid larval development in these latter species further point to the fact that they are perhaps less suitable hosts than the former species. However, despite having varying degrees of success when parasitizing different species, this wide host range may prove a useful attribute when one considers the effectiveness of other parasitoids reported on as potential biocontrol agents in the glasshouse, such as Eulophus pennicornis (Marris \& Edwards, 1995; Bell et al. 2001) and Cotesia marginiventris (Cresson), that are both highly restricted with respect to the range of hosts they will parasitize, and the stages of those species that they can develop on or within. Interesting aspects of this parasitoid's behaviour, such as its readiness to superparasitize and the persistence of supernumerary larvae within less favourable hosts strongly indicate that further investigations into the behaviour and interactions of $M$. gyrator with its various host species are warranted.

ACKNOWLEDGEMENTS. We acknowledge Plant Health Division (DEFRA) for supplying a licence to obtain and keep $C$. chalcites, S. exigua, and S. littoralis (Licence No. PHL $100 \mathrm{~B} / 3965(10 / 2001)$, amended 03/2002). This work was funded by the Pesticides Safety Directorate (DEFRA).

\section{REFERENCES}

Askari A., Mertins J. W. \& Coppel H.C. 1977: Developmental biology and immature stages of Meteorus pulchricornis in the laboratory. Ann. Entomol. Soc. Am. 70: 655-659.

Askew R.R. \& SHAw M.R. 1986: Parasitoid communities: their size, structure and development. In:. Waage J. \& Greathead D. (eds): Insect Parasitoids. $13^{\text {th }}$ Symp. R. Entomol. Soc. London. London, pp. 225-264.

Bell H.A., Marris G.C., Bell J. \& Edwards J.P. 2000A: The biology of Meteorus gyrator (Hymenoptera : Braconidae), a solitary endoparasitoid of the tomato moth, Lacanobia oleracea (Lepidoptera: Noctuidae). Bull. Entomol. Res. 90: 299-308.

Bell H.A., Smethurst F., Marris G.C. \& Edwards J.P. 2000b: Meteorus gyrator: a potential biocontrol agent against glasshouse noctuid pests. The BCPC Conference: Pests and Diseases, Vol. 1. Proc. Int. Conf. Held at the Brighton Hilton Metropole Hotel, Brighton, UK, 13-16 November. British Crop Protection Council, Farnham, UK: 2000. pp 291-296.

Bell H.A., Fitches E.C., Marris G.C., Bell J., Edwards J.P., Gatehouse J.A. \& Gatehouse A.M.R. 2001: Transgenic GNA expressing potato plants augment the beneficial biocontrol of Lacanobia oleracea (Lepidoptera: Noctuidae) by the parasitoid Eulophus pennicornis (Hymenoptera: Eulophidae). Transgenic Research 10: 34-42.

Bell H.A., Marris G.C., Smethurst F. \& Edwards J.P. 2003. The effect of host stage and temperature on selected developmental parameters of the solitary endoparasitoid Meteorus gyrator (Thun.) (Hym.: Braconidae). J. Appl. Entomol. 127: 332-339.

Corbitt T.S., Bryning G., Olieff S. \& Edwards J.P. 1996: Reproductive, developmental and nutritional biology of the 
tomato moth, Lacanobia oleracea (Lepidoptera: Noctuidae) reared on artificial diet. Bull. Entomol. Res. 86: 647-657.

Cortesero A.M. \& Monge J.P. 1994: Influence of preemergence experience on response to host and host plant odours in the larval parasitoid Eupelmus vuilleti. Entomol. Exp. Appl. 72: 281-288.

Edwards J.P., Weaver R.J. \& Marris G.C. 2001: Endocrine changes in lepidopteran larvae: potential challenges to parasitoid development and survival. In: Edwards J.P. \& Weaver R.J. (eds): Endocrine Interactions of Insect Parasites and Pathogens. BIOS, Oxford, pp 1-32.

EL-Sheikh M.A.K., Ibrahim S.M. \& EL-Maasarawy S.A.S. 1993: Food consumption and utilization in larvae of Mythimna (= Leucania) loreyi (Dup.) parasitized by Meteorus gyrator Thun. Bull. Soc. Entomol. Egypte 71: 173-184.

Foster G.N. 1981: Pest problems of glasshouse tomatoes in the West of Scotland. Proc. Crop Protection in Northern Britain, pp. 301-306.

Godfray H.C.J. 1994: Parasitoids: Behavioral and Evolutionary Ecology. Princeton Univ. Press, New Jersey, 488 pp.

Goto C., Tsutsui H. \& Hayakawa H. 1986: Parasites of some noctuid larvae in Hokkaido. II. Parasitic wasps. Jpn. J. Appl. Entomol. Zool. 3: 205-207.

Harvey J.A., Jervis M. ., Gols R., Jiang N.Q. \& Vet L.E.M. 1999. Development of the parasitoid, Cotesia rubecula (Hymenoptera: Braconidae) in Pieris rapae and Pieris brassicae (Lepidoptera: Pieridae): evidence for host regulation. $J$. Insect Physiol. 45: 173-182.

KotenKo A.G. 1976: Braconid parasites (Hymenoptera: Braconidae) of the gipsy moth Ocneria dispar L. in the south of the Ukraine. Entomol. Rev. 55: 151-158.

MarRIS G.C., \& EDWARDS J.P. 1995: The biology of the ectoparasitoid Eulophus pennicornis (Hymenoptera: Eulophidae) on host larvae of the tomato moth, Lacanobia oleracea (Lepidoptera: Noctuidae). Bull. Entomol. Res. 85: 507-513.

Poitout S. \& Bues R. 1974: Elevage de chenilles de 28 espèces de Lépidoptères et de 2 espèces d'Artiidae sur milieu artificial simple. Ann. Zool. Ecol. Anim. 6: 431-441.

Rojas M.G., Morales-Ramos J.A. \& King E.G. 1999: Response of Catolaccus grandis (Hymenoptera: Pteromalidae) to its natural host after ten generations of rearing on a factitious host Callosobrucus maculatus (Coleoptera: Bruchidae). Environ. Entomol. 28: 137-141.

Simmonds F.J. 1947: The biology of the parasites of Loxostege sticticalis, L., in North America Meteorus loxostegei, Vier. (Braconidae, Meteorinae). Bull. Entomol. Res. 38: 373-379.

SMith M.A. \& Cornell H. 1979: Hopkins host-selection in Nasonia vitripennis and its implications for sympatric speciation. Anim. Behav. 27: 365-370.

Strand M.R. \& PeCh L.L. 1995: Immunological basis for compatibility in parasitoid-host relationships. Annu. Rev. Entomol. 40: 31-56.

Thireau J.C., Reginiere J. \& Cloutier C. 1990: Biology and morphology of immature stages of Meteorus trachynotus Vier. (Hymenoptera: Braconidae). Can. J. Zool. 68: $1000-1004$.

Thompson W.R. 1953: A Catalogue of the Parasites and Predators of Insect Pests. Section 2, Part 2. Ontario, Canada, The Imperial Parasite Service, $189 \mathrm{pp}$.

VEIRE M. VAN DE 1993: $1^{\text {st }}$ Observation in glasshouse sweetpeppers in Belgium and laboratory rearing of the parasitic wasp Eulophus pennicornis (Hym.: Eulophidae). Entomophaga 38: 61-62.

VINSON S.B. \& IWANTSCH G.F. 1980: Host regulation in insect parasitoids. Quart. Rev. Biol. 55: 43-165.

Received August 11, 2003; revised December 9, 2003; accepted December 10, 200 